\title{
Keberlanjutan Agroindustri Pala Fakfak : A Sistematic Literature Review (SLR)
}

\author{
Josina Waromi \\ Jurusan Sosial Ekonomi Pertanian, Faperta-UNIPA \\ j.waromi@unipa.ac.id
}

\begin{abstract}
Abstrak
Salah satu tanaman perkebunan yang menjadi komoditi unggulan Provinsi Papua Barat adalah adalah tanaman pala yang dominan tumbuh di Kabupaten Fak-fak. Potensi pengembangan pala Fak-fak menjadi produk agroindustry yang bernilai jual tinggi dan keberlanjutannya menjadi hal yang penting. Oleh karena itu penelitian ini bertujuan mengkaji keberlanjutan agroindustry pala Fak-fak berdasarkan empat indikator yaitu ketersediaan bahan baku pala Fakfak, perubahan preferensi konsumen terhadap produk turunan pala Fakfak, karakteristik pesaing dalam agroindustry pala Fak-fak dan sumberdaya manusia yang mengolah pala Fakfak. Metode yang digunakan adalah Systematic Literature Review dengan PRISMA (Preferred Reporting items for Sistematic Review and Meta-Analysis). Hasil kajian menunjukkan bahwa dari 213 jurnal yang diunduh terdapat 17 jurnal yang meneliti tentang pala Fakfak, namun dari 17 jurnal tersebut yang memenuhi kriteria Inklusi dan Ekskluis hanya 9 jurnal. Berdasarkan 9 jurnal tersebut, menjelaskan bahwa ketersediaan Pala Fakfak sebagai bahan baku untuk kegiatan agroindustry cukup tersedia, sedangkan preferensi konsumen masih rendah dikarenakan konsistensi dalam rasa dan kemasan. Terkait pesaing dan sumberdaya manusia, diperoleh informasi bahwa pesaing dalam perdagangan buah pala berada dalam pasar Oligopsoni sedangkan pesaing produk olahan dari kegiatan agroindustry terjadi dalam pasar persaingan sempurna. Mengenai sumberdaya manusia masih perlu ditingkatkan dalam penggunaan teknologi dan managemen. Dengan demikian terkait keberlanjutan agroindustry hanya ketersediaan bahan baku yang dapat mendorong terjadi keberlanjutan agroindustry Pala Fakfak.
\end{abstract}

Kata Kunci: Keberlanjutan, Agoindustri, Pala Fakfak, Sistematic Literature Review

\section{PENDAHULUAN}

Salah satu tanaman perkebunan yang menjadi komoditi unggulan Provinsi Papua Barat adalah adalah tanaman pala. Tanaman ini banyak tumbuh di daerah Kabupaten Fakfak, Kaimana dan Teluk Bintuni. Diantara ketiga kabupaten tersebut, luas lahan Pala di Kabupaten Fakfak lebih luas 17. 560 hektar dari Kaimana 7.839 hektar dan Teluk Bintuni 139 hektar (Papua Barat dalam Angka, 2018). Tingkat produksi pala di Papua Barat pada tahun 2018 sebesar 22,63\% dari total produksi pala secara nasional sedangkan tingkat produktivitasnya mencapai $122 \%$ diatas produktivitas nasional (Pertanian.go.id, 2020). Terkait dengan ekspor, pada tahun 2018 ada eskpor pala sebesar 120 ton (0.6\% dari total ekspor nasional) dengan nilai ekspor 1.440 dollar US (Fakfak Dalam Angka, 2018).

Pala Fakfak (Myristica argantea) merupakan tanaman spesifik yang tumbuh dan berkembangbiak secara alami dan menjadi sumber penghasilan utama masyarakat di 


\section{Median Volume 13 Nomor 1 Bulan Februari 2021}

Doi http://doi.org/md.v13i1.581

Fakfak. Hal ini membuat pala menjadi symbol kebanggaan bagi daerah Fakfak (Laporan Tahutan BPTP Papua Barat, 2017). Tamalene et al. (2016) dalam Ungirwalu et al (2019) menyatakan bahwa terjaganya pala sampai dapat dimanfaatkan saat ini karena peran penting generasi terdahulu yang melindungi dan membagi pengetahuan local terkait konservasi tradisional yang disebut "sasi" dan cara pemanfaatan pala dari panen sampai pasca panen. Dogopia (2017) menjelaskan bahwa pada saat musim panen pala yaitu tiga kali setahun, maka penghasilan yang diterima oleh petani pala antara Rp 20 juta sampai Rp.25 juta rupiah, jika dihtiung per bulan maka rata-rata penghasilan petani antara Rp 1,7 juta sampai RP 2 juta.

Bagian pala yang dapat diolah sehingga memiliki nilai tambah secara ekonomi ada tiga bagian yaitu: biji pala, bunga pala/fuli (serat halus) dan buah pala (daging). Biji pala setelah mengalami proses pengolahan digunakan untuk rempah-rempah, pengharum, kosmetik dan bahan pengawet. Bagian bunga atau fuli biasanya digunakan oleh industri kosmetik untuk bahan baku kosmetika. Bagian biji dan bunga pala ini yang umumnya diperdagangkan ke Makasar, Surabaya dan Jakarta oleh pedagang antar pulau untuk kemudian diekspor atau diolah oleh industri yang membutuhkan. Selanjutnya buah pala (daging) diolah oleh industri rumah tangga skala kecil yang ada di Fakfak menjadi produk turunan seperti manisan, sirup, jus pala, selai dan kecap (ILO-PcdP2 UNDP, 2013).

Terkait dengan pengolahan buah pala (daging pala) menjadi produk lain oleh industri rumah tangga di Fakfak mengindikasikan bahwa masyarakat di Fakfak mulai terlibat dalam kegiatan agroindustri. Agroindustri di bidang pertanian dan perkebunan memberi dampak yang baik bagi petani tapi juga bagi produk pertanian atau perkebunan itu sendiri. Dampak bagi petani yaitu menolong petani dalam meningkatkan pendapatan. Dengan membeli dan menampung hasil pertanian dari petani, maka kegiataan agroindustry memberikan tambahan pendapatan bagi petani. Dampak yang lain adalah bagi produk pertanian itu sendiri yaitu meningkatkan nilai tambah dan mencegah kerusakan produk pertanian dan produk perkebunan karena sifat produk pertanian yang cepat hancur dan rusak.

Pengertian agroindustry pertama kali diungkapkan secara eksplisit oleh Austin (1981) (Rente, 2018) yaitu perusa haan yang mengolah bahan nabati dan hewani. Selanjutnya Soekartawi (Rente, 2018) juga memberi pengertian tentang agroindustry adalah perusahaan atau industri yang menjadikan produk pertanian sebagai usaha utamanya, yang mengandung arti bahwa selain sebagai bahan baku utama dalam Management Pengolahan Makanan, agroindustry juga sebagai suatu tahapan antara pembangunan pertanian dan pembangunan industri. Golber dalam Rente, 2018 menjelaskan bahwa agroindustry merupakan bagian dari industri pertanian mulai dari produksi bahan baku pertanian, industri pengolahan sampai pada penggunaannya oleh konsumen.

Melihat dampak agroindustry terhadap sector pertanian menjadi leading sector, maka keberlanjutan agroindustry harus dipertahankan. Soekartawi, 2000 dalam Udayana, 2011 menjelaskan bahwa aspek yang perlu diperhatikan dalam pengembangan 


\section{Median Volume 13 Nomor 1 Bulan Februari 2021}

Doi http://doi.org/md.v13i1.581

keberlanjutan agroindustry adalah sumber daya alam. Pemanfaatan sumberdaya alam yang menggunakan teknologi dan kelembagaan haruslah memperhatikan aspek manajemen dan konservasi sumberdaya alam serta daya dukung lingkungan. Hal ini dimaksudkan agar secara ekonomi dan social menguntungkan dan dapat diterima oleh masyarakat namun secara lingkungan tidak merusak alam. Simanjutak, 2009 dalam Rente, 2018 menyatakan beberapa ciri agroindustry berkelanjutan yaitu keuntungan dan produktivitas dapat ditingkatkan dan bertahan lama; sumberdaya pertanian dapat dijaga keberlangsungan untuk meningkatkan ketersediaan bahan baku agroindustry dan meminimalkan dampak negative dari kegiatan agroindustry terhadap pemanfaatan sumberdaya alam. Selanjutnya menurut Soekartawi dalam Rente, 2018 menyebutkan ada empat indicator keberhasilan agroinduri yang berkelanjutan. Empat indicator tersebut adalah ketersediaan bahan baku, perubahan preferensi konsumen, karakteristik pesaing dan kesiapan sumberdaya manusia.

Terkait dengan pala Fakfak sebagai komoditi unggulan di Papua Barat dan potensi pengembangan pala menjadi produk agroindustry yang bernilai jual tinggi, maka keberlanjutan agroindustry pala menjadi penting untuk dikaji. Oleh karena itu penelitian ini bertujuan mengkaji keberlanjutan agroindustry dengan menggunakan empat indicator yaitu ketersediaan bahan baku pala Fakfak, perubahan preferensi konsumen terhadap produk turunan pala Fakfak, karakteristik pesaing dalam agroindustry pala Fakfak dan sumberdaya manusia yang mengolah pala Fakfak.

\section{METODOLOGI PENELITIAN}

\section{Subjek Penelitian}

Subjek penelitian adalah data dan informasi tentang Agroindustri Pala Fakfak di Kabupaten Fakfak di Papua Barat. Alasan mengkaji Agroindustri Pala Fakfak karena nilai tambah yang ditimbulkan bagi petani dan pelaku UMKM Pala tapi juga berkontribusi bagi penerimaan daerah dan penyerapan ketenagakerjaan.

\section{Metode Penelitian}

Metode yang digunakan dalam penelitian ini adalah Metode Sistematic Literatur Review dengan PRISMA (Preferred Reporting items for Sistematic Review and MetaAnalysis). Sistematic Literatue Review adalah sebuah tinjauan pustaka yang dilakukan dengan standard yang sistematis dan ketat. Subjek dari Sistematic Literature Review adalah artikel atau jurnal yang disintesa karena bagian utama dari metode sintesa adalah Sistematic Literatur Review (Okoli and Schabram, 2010). Dengan menggunakan Sistematic Literatur Review, beberapa jurnal atau artikel disintesa untuk menjawab empat pertanyaan penelitian berikut, yaitu:

1. Apakah bahan baku untuk pengembangan Agroindustri Pala Fakfak cukup tersedia?

2. Apakah ada perubahan preferensi konsumen terhadap hasil Agroindustri Pala Fakfak?

3. Seperti apa karakteristik pesaing dalam pengembangan Agroindustri Pala Fakfak? 


\section{Median Volume 13 Nomor 1 Bulan Februari 2021}

Doi http://doi.org/md.v13i1.581

4. Apakah sumberdaya manusia cukup memadai untuk pengembangan Agroindustri Pala Fakfak?

Setelah menentukan pertanyaan penelitian, langkah selanjutnya adalah melakukan proses pencarian. Proses pencarian dilakukan untuk mendapatkan informasi dan data yang relevan dengan pertanyaan penelitian. Proses pencarian data dan informasi dilakukan menggunakan mesin pencari Google Scholar yang diunduh melalui Perish or Publish dan disimpan dalam perangkat lunak yaitu Mendeley.

Langkah selanjutnya menentukan protocol Sistematic Literature Review. Dalam protocol Sistematic Literature Review, ada 5 tahapan yang harus dilakukan yaitu:

1. Mendefinisikan kriteria kelayakan

2. Mendefinisikan sumber informasi

3. Pemilihan literatur

4. Pengumpulan data

5. Pemilihan item data

Pada tahap 1, kriteria kelayakaan ada dua yaitu:

1. Data yang digunakan berada dalam rentang waktu 2015-2019

2. Data diperoleh Google Scholar yang diunduh melalui Perish or Publish

3. Artikel yang digunakan hanyalah jurnal yang membahas Agroindustri Pala Fakfak

4. Artikel ditulis dalam Bahasa Inggris dan Bahasa Indonesia

Pada tahap 2, sumber informasi berasal dari mesin pencari yaitu google scholar yang diunduh melalui Perish or Publish dan disimpan dalam perangkat lunak yaitu Mendeley.

Pada tahap 3, pemilihan literatur dilakukan dengan penentuan kata kunci. Karena penelitian ini adalah Keberlanjutan Agroindustry Pala Fakfak maka kata kunci yang digunakan dalam dua bahasa yaitu Bahasa Indonesia dan Bahasa Inggris. Dalam Bahasa Indonesia, kata kunci adalah agroindustry, keberlanjutan dan Pala Fakfak sedangkan dalam bahasa Inggris seperti sustainability, agroindustry dan Papua nutmeg.

Pada tahap 4, adalah tahap pengumpulan data. Data yang dikumpulkan dalam penelitian ini adalah hasil penelitian yang telah dipublikasi lewat jurnal. Caranya yaitu melalui Publish or Perish, memilih engine Google Scholar, mengetik kata kunci dalam dua bahasa memilih tahun 2015-2019 lalu didokumentasi dalam perangkat lunak yaitu Mendeley.

Pada proses pencarian melalui google scholar menggunakan kata kunci dalam Bahasa Indonesia yaitu keberlanjutan, Agroindustri dan Pala Fakfak, dan dalam Bahasa Inggris, sustainability, agro-industry dan Papua nutmeg, maka ditemukan 213 jurnal. Setelah proses pencarian dilanjutkan dengan proses seleksi sesuai kriteria Inklusi dan Ekslusi. Kriteria inklusi adalah jurnal yang menjelaskan Pala Fakfak secara umum dalam bahasa Indonesia maupun bahasa inggris, sedangkan kriteria eksklusi adalah jurnal yang memenuhi kriteria inklusi dan menjelaskan empat pertanyaan penelitian. Proses penentuan jurnal yang memenuhi kriteria inklusi dan ekslusi dilakukan dengan teknik membaca cepat keseluruhan isi jurnal. Jumlah jurnal yang memenuhi kriteria inklusi dan ekslusi disajikan pada tabel.1. 


\section{Median Volume 13 Nomor 1 Bulan Februari 2021}

Doi http://doi.org/md.v13i1.581

Tabel 1. Jumlah Jurnal yang memenuhi kriteria inklusi dan eksklusi

\begin{tabular}{clcc}
\hline No & & Jurnal & Jumlah Jurnal \\
\hline 1 & Kriteria Inklusi & 17 \\
2 & Kriteria Eksklusi & 9 \\
\hline
\end{tabular}

Berdasarkan tabel 1 terlihat bahwa dari 213 jurnal yang diperoleh dari Google Scholar yang mengkaji tentang Agroindustri Pala Fakfak dan keberlanjutannya hanya 17 jurnal. Selanjutnya dari 17 jurnal tersebut yang dapat menjelaskan empat pertanyaan penelitian hanya 9 jurnal. Dengan demikian dalam proses pembahasan hanya menggunakan 9 jurnal tersebut.

Tabel 2. Jumlah Jurnal yang sesuai dengan Kriteria dan Batasan

\begin{tabular}{|c|c|c|}
\hline No & Publikasi & Jumlah \\
\hline 1 & $\begin{array}{l}\text { Risalah Kebijakan Pertanian dan Lingkungan Vol. } 3 \text { No. } 2 \text {, Agustus } \\
\text { 2016: 140-152 ISSN : 2355-6226 E-ISSN : 2477-0299 }\end{array}$ & 1 \\
\hline 2 & Jurnal Littri 19(2), Juni 2013. Hlm. 72 - 77 ISSN 0853-8212 & 1 \\
\hline 3 & $\begin{array}{l}\text { Jurnal Teknik ITS ( Vol.8, No.2 ( 2019) ISSN : 2337-3539 (2301- } \\
9271 \text { print) }\end{array}$ & 1 \\
\hline 4 & $\begin{array}{l}\text { Jurnal Ilmu Kehutanan Journal of Forest Science } \\
\text { https://jurnal.ugm.ac.id/jikfkt }\end{array}$ & 1 \\
\hline 5 & IOP Conf. Series: Earth and Environmental Science. IOP Publishing & 2 \\
\hline 6 & Agroindustrial Technology Journal 03 (02) & 1 \\
\hline 7 & Buletin Agro-Infotek $2(1), 2016$ & 1 \\
\hline 8 & $\begin{array}{l}\text { e-ISSN : } 2527-564 X \text { Website Journal : http://www.ejournal- } \\
\text { academia.org/index.php/renaissance }\end{array}$ & 1 \\
\hline 9 & JUMABIS (JURNAL MANAJEMEN \& BISNIS & 1 \\
\hline
\end{tabular}

Dari 9 jurnal tersebut, hanya jurnal IOP Conference Series: Earth and Environmental Science IOP Publishing yang memuat kajian tentang Pala Fakfak sebanyak dua kali. Hal ini dikarenakan adanya kegiatan konferensi yang dilakukan berseri sehingga memberi kesempatan bagi penulis mengirimkan tulisan pada konferensi tersebut.

Selanjutnya dari 9 jurnal tersebut tidak semuanya membahas semua pertanyaan penelitian. Hal ini dapat dilihat pada table 3 .

Tabel 3. Jumlah Jurnal Yang Membahas Pertanyaan Penelitian (RQ)

\begin{tabular}{ccc}
\hline No & \multicolumn{1}{c}{ Pertanyaan Penelitian } & $\begin{array}{c}\text { Jumlah } \\
\text { Jurnal }\end{array}$ \\
\hline 1. & $\begin{array}{l}\text { RQ 1: Apakah bahan baku untuk pengembangan Agroindustri Pala } \\
\text { Fakfak cukup tersedia? }\end{array}$ & 3 \\
2. & $\begin{array}{l}\text { RQ 2: Apakah ada perubahan preferensi konsumen terhadap hasil } \\
\text { Agroindustri Pala Fakfak? }\end{array}$ & 2 \\
3. & $\begin{array}{l}\text { RQ 3: Seperti apa karakteristik pesaing dalam pengembangan } \\
\text { Agroindustri Pala Fakfak? }\end{array}$ & 3 \\
4. & $\begin{array}{l}\text { RQ 4: Apakah sumberdaya manusia cukup memadai untuk } \\
\text { pengembangan Agroindustri Pala Fakfak? }\end{array}$ & 2 \\
\hline
\end{tabular}


Terdapat 2- 3 jurnal dapat menjelaskan 4 pertanyaan penelitian. Hal ini dikarenakan satu jurnal bisa menjelaskan satu sampai dua pertanyaan penelitian. Rumusan penelitian dan pertanyaan penelitian pada jurnal terpilih yang telah memenuhi kriteria ekslusi tidak persis dengan empat pertanyaan penelitian pada kajian ini namun penjelasannya dapat mengarah ke satu atau dua pertanyaan penelitian dalam kajian ini.

\section{Pada tahap 5, yaitu analisa data}

Setelah melakukan proses pencarian jurnal dan disesuaikan dengan kriteria yang telah ditentukan, maka selanjutnya pembahasan secara deskriptif menjawab pertanyaan penelitian yang disajikan dalam bentuk tabulasi.

\section{HASIL DAN PEMBAHASAN}

Pembahasan dalam kajian ini meliputi empat pertanyaan penelitian yang secara terperinci diuraikan sebagai berikut:

\section{Ketersediaan Bahan Baku Untuk Pengembangan Agroindustri Pala Fakfak}

Bahan baku adalah bahan utama yang digunakan dalam membuat produk turunan dari bahan utama tersebut. Bahan baku dalam kajian ini adalah buah pala Fakfak. Dari sembilan jurnal, hanya tiga jurnal yang menjelaskan ketersediaan pala Fakfak.

Tabel. 4. Kategori Jurnal yang Menjelaskan Pertanyaan Penelitian Pertama

\begin{tabular}{clc}
\hline No & \multicolumn{1}{c}{ Kategori Jurnal } & Jumlah Jurnal \\
\hline 1 & Penjelasan Ketersediaan Bahan Baku & 3 \\
2 & Tidak ada penjelasan ketersediaan Bahan Baku & 6 \\
\hline & Total Jurnal & 9 \\
\hline
\end{tabular}

Dalam kajian Andrianto dan Rahardja (2016) menjelaskan bahwa sumber buah pala Fakfak sebagian besar berasal dari hutan pala yang merupakan warisan secara turun temurun dari orang tua ke generasi berikutnya, sedangkan lainnya berasal dari perkebunan pala yang baru dikembangkan belakang ini oleh pemerintah daerah. Meskipun pola pengembangan perkebunan rakyat masih konvensional, namun pola perkebunan harus diperkenalkan ke masyarakat karena merupakan sesuatu proses yang baru bagi masyarakat. Oleh sebabnya diperlukan adanya sosialisasi cara budidaya yang tepat agar produktivitas pala meningkat.Terkait dengan pengembangan Agroindustri Pala Fakfak dalam Andrianto dan Rahardja (2016) juga menjelaskan bahwa ketersediaan bahan baku untuk industri kecil sudah mencukupi hal ini disebabkan produksi pala Fakfak dapat dipanen minimal dua kali dalam setahun. Daging buah pala Fakfak memiliki keunggulan lebih dibandingkan pala Banda. Hal ini ini dikarenakan daging buah yang besar, aroma lebih tajam dan tidak sepat. Produk yang sudah dikembangkan antara lain sirup, manisan, kecap, dan permen. Namun dalam hal pengemasan belum dikemas sesuai standard serta mengalami kesulitan dalam pengadaan botol untuk sirup.

Hasil Penelitian Pratama et al, 2020 menyebutkan bahwa produksi tanaman pala Fakfak meningkat seiring bertambahnya umur pohon pala. Saat umur 7 tahun, tanaman 
pala fakfak mulai berbuah sampai mencapai maksimum di usia 25 tahun. Selanjutnya pala fakfak masih terus berbuah meskipun telah mencapai umur 60-70 tahun. Dalam setahun, buah pala Fakfak bisa dipanen beberapa kali yaitu pada bulan Maret-April, bulan Juni-Juli dan bulan November-Desember. Namun diluar musim panen yang sudah dijelaskan sebelumnya ada juga panen yang disebut panen matahari karena waktu panen saat musim kemarau meskipun hasil panen tidak sebanyak panen pada bulan-bulan panen. Ada peluang bagi perkembangan industry di Fakfak untuk pengolahan daging buah pala karena tersedianya bahan bahan baku yang melimpah.

\section{Perubahan Preferensi Konsumen Terhadap Hasil Agroindustri Pala Fakfak}

Preferensi konsumen mengarah pada kepuasan permintaan konsumen terhadap suatu produk Agroindustri. Permintaan konsumen meliputi permintaan individu, permintaan rumah tangga, permintaan institusi maupun permintaan luar negeri. Preferensi dalam kajian ini mengarah pada kepuasan konsumen terhadap hasil agroindustry pala Fakfak. Dari Sembilan jurnal, ada 2 jurnal yang membahas tentang preferensi konsumen terhadap produk olahan pala Fakfak.

Tabel.5. Kategori Jurnal yang Menjelaskan Pertanyaan Penelitian Kedua

\begin{tabular}{ccc}
\hline No & Kategori Jurnal & Jumlah Jurnal \\
\hline 1 & Penjelasan tentang perubahan preferensi konsumen & 2 \\
2 & Tidak ada Penjelasan tentang perubahan preferensi konsumen & 7 \\
\hline & Total Jurnal & 9 \\
\hline
\end{tabular}

Terkait dengan preferensi atau kepuasan terhadap produk turunan pala seperti sirup pala, dijelaskan bahwa antara satu sirup dengan sirup yang lain belum ada konsistensi dalam hal rasa dikarenakan komposisi bahan pembuat sirup yang tidak seragam termasuk ketersediaannya di hotel maupun restoran belum kontinyu. Selain itu kadang tali kemasan bungkusan sirup bermasalah dan penutup botol yang kurang rapat sehingga kadang bocor saat diletakkan dalam posisi tidur. Pada label sirup belum dicantumkan manfaat sirup pala bagi konsumen bahkan kadang lupa mencantumkan tanggal kadaluarsa. Untuk manisan basah bisa terfermentasi dan tidak tahan waktu khususnya jika dibeli oleh penumpang kapal laut selain itu manisan basah kadang lengket di tangan. Untuk kecap pala belum dijual umum karena bersaing dengan merk dan harga kecap yang sudah beredar, sehingga kecap ditargetkan sebagai oleh-oleh bagi wisatawan yang berkunjung ke Fakfak (Andrianto dan Rahardja, 2016).

Ketika ada keluhan dari pelanggan maka pelaku agroindustry pala Fakfak melakukan perbaikan terus menerus. Misalnya, produk olahan pala merek Saripala terus melalukan perbaikan sesuai permintaan atau keluhan dari pelanggannya (Andrianto, dan Rahardja, 2016).

\section{Karakteristik Pesaing Dalam Pengembangan Agroindustri Pala Fakfak}

Karakteristik pesaing dalam pengembangan Agroindustri pala Fakfak dalam kajian ini mengarah pada pelaku-pelaku dalam pemasaran pala Fakfak, seperti bersifat 
monopsoni, duopsoni atau oligopsoni. Dari Sembilan jurnal, terdapat 3 jurnal yang menjelaskan karakteristik pesaing dalam pengembangan agroindustry pala fakfak.

Tabel 6. Kategori Jurnal yang Menjelaskan Pertanyaan Penelitian Ketiga

\begin{tabular}{cc}
\hline \multicolumn{1}{c}{ Kategori Jurnal } & Jumlah Jurnal \\
\hline Menjelaskan karakteristik pesaing & 3 \\
Tidak ada penjelasan karaktersitik pesaing & 6 \\
\hline Total Jurnal & 9 \\
\hline
\end{tabular}

Karakteristik pesaing pemasaran buah pala fakfak dominan oligopsoni, karena terdapat beberapa pembeli yang sebenarnya adalah pelaku usaha di daerah Fakfak tapi juga pelaku usaha perdagangan antar pulau. Meskipun hanya beberapa pembeli tapi pembeli tersebut yang menguasai pasar pala di Kabupaten Fakfak. Sedangkan karakteristik pesaing agroindustry pala atau produk olahan pala fakfak lebih cenderung pada pasar persaingan terbuka.

Dalam artikel Andrianto, S, M dan Rahardja, S, (2016) menyatakan bahwa pada tahun 1970- 1990an, pengusaha local asal Fakfak dapat mengekspor pala secara langsung ke ke Singapura, Hongkong dan Eropa. Namun dengan adanya kebijakan ekspor satu pintu, maka kegiatan ekspor tidak dapat dilakukan secara langsung tapi dilakukan melalui pedagang perantara di Surabaya. Selain kebijakan satu pintu, terdapat juga kelompok kecil atau diistilahkan sebagai mafia kecil juga menghambat perdagangan pala Fakfak sebagai komoditas ekspor. Kondisi ini cukup berdampak pada petani pala dan pengusaha local asal Fakfak. Dogopia A (2017) menjelaskan bahwa masyarakat terpaksa menjual pala kepada pedagang dengan harga yang kurang memuaskan karena tidak ada pilihan untuk memasarkan hasil panen pala. Masyarakat asli yang merupakan petani pemilik kebun pala menjual seluruh hasil panen kepada pedagang pala antar daerah.

Dalam artikel Gusti Randy Pratama, R, G, Harahap, M, A dan Muhandri, Tjahja (2019) menjelaskan bahwa dalam rantai nilai pala ada petani pala, pengumpul local dan pedagan antar pulau. Pengumpul local mulai mengunjungi petani pala di kebun-kebun mereka saat pala siap dipanen dengan harga yang rendah. Selanjutnya pengumpul local ini menjual pala yang dibeli dari petani ke pedagang antar pulau. Pengumpul local dan pendagang antar pulau telah terjalin suatu hubungan yang kuat sehingga pedagang antar pulau dapat meminjamkan modal bagi pengumpul local untuk membeli pala di tingkat petani. Dogopia A (2017) menyebutkan bahwa karakteristik pedagang pengumpul dan pembeli pala di Fakfak adalah pedagang musiman dan juga mereka yang sudah lama berprofesi sebagai pedagang.

Jumlah pedagang antar pulau yang tinggal di Fakfak berjumlah kurang lebih 10 pedagang. Pedagang pala antar daerah ini didominasi oleh para pendatang dari berbagai suku di Indonesia dan mereka juga yang mendominasi pembelian pala Fakfak. Pelaku pedagang antar pulau inilah yang memiliki gudang-gudang penampung pala di Fakfak. Akses pasaran ke luar Papua seperti Jakarta, Semarang dan Surabaya diketahui oleh 


\section{Median Volume 13 Nomor 1 Bulan Februari 2021}

Doi http://doi.org/md.v13i1.581

pedagang antar pulau karena mereka bermitra dengan para eksportir di luar Papua (Dogopia A, 2017; Gusti Randy Pratama, R, G, Harahap, M, A dan Muhandri, Tjahja, 2019).

Selain pedagang ada juga Badan Usaha Milik Kampung (BUMKAM) semacam perusahaan desa (Gusti Randy Pratama, R, G, Harahap, M, A dan Muhandri, Tjahja, 2019) yang juga membeli pala dari petani lalu dijual ke pedagang antar pulau. Harga yang diberikan lebih tinggi dari pedagang, sehingga hal ini memberi pilihan bagi petani untuk menjual pala.

Karakteristik pesaing produk olahan dari pala atau agroindustry pala Fakfak dilihat dari segmentasi pasar. Segmentasi pasar produk olahan pala Fakfak terdiri dari masyarakat di Kabupaten Fakfak, penumpang yang berangkat menggunakan pesawat maupun kapal laut, olahragawan, hotel, restoran, warung makan dan kios. Selain pameran di luar Fakfak maupun di luar Papua juga menjadi target penjualan produk agroindustry pala fakfak. Produk olahan pala Fakfak saat ini masih berupa makanan yang sifatnya sebagai oleh-oleh atau makanan ringan yang pengemasannya masih sederhana dan belum terlalu menarik. Produk olahan dari pala Fakfak antara lain manisan basah dan manisan kering, permen pala, sirup, dan kecap. Meskipun beberapa merek pala sudah melakukan penjualan dengan sistem konsinyasi antara lain Kopindra Bina Teratai yang dititipkan di beberapa toko, Bandara Torea, pusat olahragawan seperti kolam renang dan fitness center, bentuk pemasaran lain seperti pemasaran dari mulut ke mulut (word of mouth) juga tetap dilakukan (Andrianto S, M dan Rahardja S ,2016). Pada artikel Gusti Randy Pratama, R, G, Harahap, M, A dan Muhandri, Tjahja (2019) disebutkan bahwa produk turunan dari daging pala berupa manisan, sirup, jus buah dan kecap dijual oleh koperasi dengan target adalah para wisatawan yang sedang berada di Fakfak.

\section{Sumberdaya Manusia Untuk Pengembangan Agroindustri Pala Fakfak}

Sumberdaya manusia yang cukup memadai dalam pengembangan agroindustry pala fakfak merujuk pada kemampuan petani atau pelaku agroindustry pala mengolah pala fakfak sehingga menghasilkan produk olahan yang bernilai jual tinggi. Kemampuan dilihat dari penguasaan teknologi dan managemen dalam agroindustry pala fakfak. Berdasarkan 9 jurnal, ada 2 jurnal yang menjelaskan kemampuan masyarakat atau pelaku mengolah pala Fakfak.

Tabel 7. Kategori Jurnal yang Menjelaskan Pertanyaan Penelitian Keempat

\begin{tabular}{|c|c|}
\hline Kategori Jurnal & Jumlah Jurnal \\
\hline $\begin{array}{l}\text { Penjelasan kemampuan pelaku mengolah pala fakfak menghasilkan } \\
\text { produk olahan yang bernilai jual tinggi }\end{array}$ & 2 \\
\hline $\begin{array}{l}\text { Tidak ada penjelasan kemampuan pelaku mengolah pala fakfak } \\
\text { menghasilkan produk olahan yang bernilai jual tinggi }\end{array}$ & 7 \\
\hline Total Jurnal & 9 \\
\hline
\end{tabular}


Pengembangan pala Fakfak menjadi produk olahan yang bernilai jual tinggi belum banyak dilakukan oleh masyarakat, padahal masyarakat Fakfak mengetahui bahwa terdapat 36 potensi produk olahan dari pala namun produk olahan yang baru dihasilkan hanya beberapa saja berupa manisan basah dan kering, sirup, permen dan kecap. Dari produk yang sudah dihasilkan, standar dan kemasan produk masih harus terus diperbaiki dan ditingkatkan. Hal ini dikarenakan pegolahan pala menjadi produk olahan lain masih dilakukan secara konvensional berdasarkan pengetahuan local masyarakat dan penguasan teknologi yang masih terbatas (Andrianto dan Rahardja, 2016).

Hasil penelitian Pratama et al (2019) menjelaskan bahwa belum ada industri rumah tangga di Kabupaten Fakfak yang mengolah buah pala menjadi minyak esensial.

\section{KESIMPULAN}

Berdasarkan kajian Sistematic Literature Review dengan PRISMA disimpulkan bahwa:

1. Dalam kajian ini hanya menggunakan 9 jurnal dari total 213 jurnal yang memenuhi kriteria inklusi dan ekslusi untuk menjawab empat pertanyaan penelitian.

2. Pala Fakfak sebagai bahan baku kegiatan agroindustry di Fakfak cukup tersedia.

3. Preferensi konsumen terhadap produk agroindustry Pala Fakfak masih rendah karena belum konsisten dalam rasa dan kemasan.

4. Pesaing perdagangan buah pala berada dalam pasar Oligopsoni sedangkan pesaing perdagangan produk agroindustry buah pala berada dalam pasar persaingan sempurna.

5. Pengembangan sumberdaya manusia terus ditingkatkan terutama penggunaan teknologi dan manajemen.

6. Hanya satu indicator yang memenuhi keberlanjutan agroindustry Pala Fakfak yaitu ketersediaan bahan baku.

\section{DAFTAR PUSTAKA}

Andrianto Syaefudin Mokhamad Dan Rahardja Sapta, 2016. Formulasi Strategi Pengembangan Agroindustri Pala Fakfak. Risalah Kebijakan Pertanian Dan Lingkungan Vol. 3 No. 2, Agustus 2016: 140-152 ISSN : 2355-6226 E-Issn : 2477-0299. Https://Dx.Doi.Org/10.20957/Jkebijakan.V3i2.15514

BPS, 2018. Kabupaten Fakfak Dalam Angka. Penerbit Badan Pusat Statistik Kabupaten Fakfak.

BPS, 2018. Papua Barat dalam Angka.Penerbit Badan Pusat Statistik Provinsi Papua Barat bekerja sama dengan BAPPEDA Papua Barat.

Dogopia Albertus, 2017. Peranan Pemerintah Daerah Dalam Pemberdayaan Petani Pala Di Kabupaten Fakfak. Jurnal Renaissance | Volume 2 No. 02 | Agustus 2017, hlm: 194-208. e-ISSN: 2527-564X Website Journal : http://www.ejournalacademia.org/index.php/renaissance 


\section{Median Volume 13 Nomor 1 Bulan Februari 2021}

Doi http://doi.org/md.v13i1.581

E Triandini E, Jayanatha S, Indrawan A, G W Putra W G dan Iswara B, 2019. (Metode Systematic Literature Review untuk Identifikasi Platform dan Metode Pengembangan Sistem Informasi di Indonesia) Metode Systematic Literature Review untuk Identifikasi Platform dan Metode Pengembangan Sistem Informasi di Indonesia. Indonesian Journal of Information Systems (IJIS) Vol. 1, No. 2, Februari 2019

Hammar R.K. Roberth, 2009. PROSES PERALIHAN HARTA WARIS PADA SUKU IHANDIN FAKFAK PAPUA BARAT. PATRIOT Volume 2 Nomor 1 Juni 2009 P-ISSN: 1979-7087. Diterbitkan oleh: Sekolah Tinggi Ilmu Hukum (STIH) Bintuni.

Hay Klara dan Aulia Ulfa Belinda, 2019. Analisis Lokasi Pengembangan Sub Sistem Agropolitan Berbasis Komoditas Pala di Kabupaten Fakfak. Jurnal Teknik ITS ( Vol.8, No.2 ( 2019) ISSN : 2337-3539 (2301-9271 print)

ILO - PCdP2 UNDP,2013. Kajian Pala dengan Pendekatan Rantai Nilai dan Iklim Usaha di Kabupaten Fak-fak LAPORAN STUDI. "Program Pembangunan berbasis Masyarakat Fase II: Implementasi Institusionalisasi Pembangunan Mata Pencaharian yang Lestari untuk Masyarakat Papua"

Kitchenham Barbara, Brereton O.Pearl, Budgen David ,Turner Mark ,Bailey John, Stephen Linkman Stpehen, 2010. A Systematic literature reviews in software engineering - Journal homepage: $\mathrm{www}$.elsevier.com/locate/infsof

Laporan Tahutan BPTP Papua Barat, 2017. Balai Pengkajian Teknologi Pertanian Papua Barat Balai Besar Pengkajian Dan Pengembangan Teknologi Pertanian Badan Penelitian Dan Pengembangan Pertanian Kementerian Pertanian 2017.

Luna P, Agustinisari I dan Hernani, 2019. Characterization of Monodiacylglycerol (MDAG) Synthesized from Papua Nutmeg (Myristica Argantea Warb). IOP Conf. Series: Earth and Environmental Science 309 (2019) 012067 IOP Publishing. 2nd International Conference on Agriculture Postharvest Handling and Processing. DOI :10.1088/1755-1315/309/1/012067 .

M A'mun, 2013. Karakteristik Minyak Dan Isolasi Trimiristin Biji Pala Papua (Myristica argentea) Characteristics of Oil and Trimyristin Isolation of Papua Nutmeg Seeds (Myristica argentea. Jurnal Littri 19(2), Juni 2013. Hlm. 72 - 77 ISSN 0853-8212.

Nonce Oktavina Lakupais Oktavina Nonce dan Wanma R. Johanis, 2019. Analisis Pendapatan Petani Pala Di Kampung Brongkendik Distrik Fakfak Tengah Kabupaten Fakfak,PP 8 - 24. JUMABIS (JURNAL MANAJEMEN \& BISNIS)

Napitulu Darmawan, 2020. Systematic Literature Review Based on PRISMA. Dipaparkan pada Workshop Daring Systematic Literature Review (SLR) 20-21 Juni 2020

Okoli Chitu and Schabram Kira,2010. A Guide to Conducting a Systematic Literature Review of Information Systems Research. Working Papers on Information Systems ISSN 1535-6078. Permanent URL: http://sprouts.aisnet.org/10-26 
Pertanian.go.id. Direktorat Jenderal Perkebunan. www.pertanian.go.id/home/index.php?show=repo\&fileNum=219

Pratama Randi, Harahap Musa Ali, Muhandri Tjahja, 2019. Value Chain Study Of Papua Nutmeg In Fakfak District: Studi Rantai Nilai Pala Papua di Kabupaten Fakfak . Agroindustrial Technology Journal 03 (02) (2019) 51 - 61 51. DO1 http://dx.doi.org/10.21111/atj.v3i2.3794

Rente A (2016) Pengantar Agroindustri. Mujahid Press

Rouw Aser dan Atekan,2015. Peranan Data Dan Informasi Pemetaan AEZ 26: Peranan Data Dan Informasi Pemetaan Aez (Agro Ecological Zone) Bagi Pembangunan Pertanian Berkelanjutan: Kasus Wilayah Papua Barat. Buletin Agro-Infotek 1 (1) 2015.

Sutisna Entis dan Motulo F.J Hiasinta, 2015. Pengembangan Pertanian Bioindustri Di Papua Barat : Konsep, Peluang, Dan Implementasi. Buletin Agro-Infotek 1 (1),2015.

Sutisna Entis, 2016. Membangun "Kampung Pala" Berwawasan Pertanian Bioindustri Di Kabupaten Fakfak Papua Barat. Buletin Agro-Infotek 2 (1) , 2016

Subhan Muh. dan Basri Hasan (2019). Klasifikasi Mutu Buah Pala (Myristica Fragrans Houtt) Berbasis Pengolahan Citra Menggunakan Metode Deep Learning Arsitektur Faster R-CNN INTEK Jurnal Penelitian. 2019, Volume 6 (2): 106-113 106. DOI: http://dx.doi.org/10.31963/intek.v6i2.1566

Ungirwalu Antoni, Awang Afri San, Maryudi Ahmad, dan Suryanto Priyono, 2019. Small Scale Ecology and Society: Forest-Culture of Papua Nutmeg (Myristica argentea Warb.) Ekologi dan Masyarakat Skala Lokal: Hutan Budidaya Pala Papua (Myristica argentea Warb.) Jurnal Ilmu Kehutanan Journal of Forest Science https://jurnal.ugm.ac.id/jikfkt

Udayana, I. G. B. U. (2011). Peran agroindustri dalam pembangunan pertanian. Singhadwala, 44, 3-8.

Wahyuni S, and Bermawie N,2020. Yield and fruit morphology of selected high productive Papua nutmeg trees (Myristica argentea Warb.) IOP Conference Series: Earth and Environmental Science PAPER - OPEN ACCESS To cite this article: IOP Conf. Ser.: Earth Environ. Sci. 418012032.

Yuanja Pandu, 2018. Mengejar Ketertinggalan: Menggali Potensi Sektor Agribisnis Kabupaten Fakfak, Provinsi Papua Barat. Jurnal Natapraja Kajian Ilmu Administrasi Negara. Dipublikasikan oleh JIAN FIS UNY Vol. 6, No. 1, 2018 https://journal.uny.ac.id/index.php/natapraja pp. 99-114. 